\title{
Bioactive Bioflavonoids from Platonia insignis (Bacuri) Residues as Added Value Compounds
}

\author{
Dayane C. Ribeiro, ${ }^{\sharp a, b}$ Helena M. Russo, ${ }^{\circledR \#, a}$ Karina Fraige, ${ }^{\circledR a}$ Maria L. Zeraik, ${ }^{\circ}$ \\ Cláudio R. Nogueira, ${ }^{\circledR d}$ Patrícia B. da Silva, ${ }^{e}$ Ana C. Codo, ${ }^{f}$ Giovana M. F. Calixto, ${ }^{b}$ \\ Alexandra I. de Medeiros, ${ }^{\circ f}$ Marlus Chorilli ${ }^{\circledR b}$ and Vanderlan S. Bolzani ${ }^{\circledR *, a}$ \\ ${ }^{a}$ Núcleo de Bioensaios, Biossíntese e Ecofisiologia de Produtos Naturais (NuBBE), \\ Departamento de Química Orgânica, Instituto de Química, \\ Universidade Estadual Paulista “Júlio de Mesquita Filho" (Unesp), 14800-900 Araraquara-SP, Brazil \\ ${ }^{b}$ Departamento de Fármacos e Medicamentos, Faculdade de Ciências Farmacêuticas, \\ Universidade Estadual Paulista “Júlio de Mesquita Filho” (Unesp), 14800-903 Araraquara-SP, Brazil \\ 'Laboratório de Fitoquímica e Biomoléculas (LabFitoBio), Departamento de Química, \\ Universidade Estadual de Londrina (UEL), 86051-990 Londrina-PR, Brazil \\ ${ }^{d}$ Faculdade de Ciências Exatas e Tecnologia (FACET), \\ Universidade Federal da Grande Dourados (UFGD), 79804-970 Dourados-MS, Brazil \\ eDepartamento de Genética e Morfologia, Universidade de Brasília (UnB), 70910-970 Brasília-DF, Brazil \\ ${ }^{f}$ Departamento de Ciências Biológicas, Faculdade de Ciências Farmacêuticas, \\ Universidade Estadual Paulista "Júlio de Mesquita Filho" (Unesp), 14800-900 Araraquara-SP, Brazil
}

\begin{abstract}
Platonia insignis fruit, popularly known as bacuri, is traditionally used in folk medicine for its anti-inflammatory and antioxidant properties. Therefore, this study determined the chemical composition and biological activities of the bacuri's shell and seeds extracts, considered residues from its consumption and industrial uses. Four biflavonoids (GB-2a, GB-1a, morelloflavone, and volkensiflavone) were identified in the extracts by high-performance liquid chromatography-diode array detection (HPLC-DAD), liquid chromatography tandem mass spectrometry (LC-MS/MS), and liquid chromatography-solid phase extraction-nuclear magnetic resonance (LC-SPE-NMR) techniques. Morelloflavone was identified as the main compound in the shell ethyl acetate extract, being responsible for the high in vitro antioxidant $\left(50 \%\right.$ effective concentration $\left(\mathrm{EC}_{50}\right)$ ranging from 8.0-10.5 $\mu \mathrm{g} \mathrm{mL}^{-1}$ in different protocols), anti-glycant (80\%), and moderate inhibition of nitric oxide $\left(1.56 \mu \mathrm{g} \mathrm{mL} \mathrm{m}^{-1}\right.$ for $>90 \%$ cell viability) activities. This extract showed promising in vivo anti-inflammatory activity evaluated through the paw edema protocol after its incorporation into a liquid-crystalline drug carrier system, reducing the edema by up to $31 \%$. The results demonstrated the potential of the fruit for the development of drugs of natural origin and corroborated to add economic value to these discarded residues.
\end{abstract}

Keywords: Platonia insignis, Clusiaceae, biflavanones, liquid-crystalline system, bioactivities

\section{Introduction}

According to the World Health Organization (WHO), between 2000 and 2015, the world's life expectancy has risen at five years, surpassing the 80 years' mark in some countries. This current growth can be attributed mainly due to the advances in science and technology that have led to

*e-mail: vanderlan.bolzani@unesp.br

\#These authors contributed equally to this work. a significant improvement in the quality of life and disease prevention. In fact, there was a significant increase in the number of diseases, especially those related to common aging disorders, and as a reflection of this new reality, studies aiming the development of new drugs are being carried out all over the world. ${ }^{1}$ In this context, tropical fruits represent an original and valuable source for the discovery of new therapeutic agents since they may contain numerous pharmacologically active compounds and present potential for the development of new medicines. ${ }^{2}$ 
The Platonia insignis Mart. species, popularly known as "bacurizeiro", is an example of this potential still to be explored. This species belongs to the Clusiaceae family and is considered a large fruity tree, which is also used for wood extraction, being found predominantly in Brazilian northern and northeastern regions. ${ }^{3}$

The bacuri, $P$. insignis fruit, is very consumed by the population from the Amazon region, both in natura and in the manufacture of sweets, jams, and ice creams, presenting great importance to the local market. Morphologically, the fruit is a single-billed berry, is about $10 \mathrm{~cm}, 100 \mathrm{~g}$, rounded, oval or flattened, ${ }^{4}$ and is composed by one to five seeds enveloped by the endocarp, the edible part, which represents only $3-4 \%$ of the total fruit mass. Therefore, it can be said that this fruit is, in mass, predominantly composed of shell and seed. Folk medicine describes the use of this species as healing, antimicrobial, antitumor, antioxidant and anti-inflammatory source, ${ }^{4,5}$ and for the treatment of skin diseases and diarrhea. ${ }^{6}$

The literature reports promising results of the extracts and isolated compounds of $P$. insignis, containing a range of biological activities, such as reduction of oxidative stress, ${ }^{7-9}$ enzymatic inhibition of $\alpha$-glucosidase and acetylcholinesterase, ${ }^{10,11}$ immuno-modulatory effects and low in vivo toxicity. ${ }^{12}$ Bacuri's seeds are rich sources of fatty acids, triacylglycerols and xanthones that exhibit antiepileptic and antiparasitic effects, ${ }^{13,14}$ and polyisoprenylated benzophenones, with vasorelaxant effect in animal models..$^{15}$ The compounds 1,3-distearyl2-oleylglycerol (TG1), 2-oleyl-1,3-dipalmitoyl-glycerol (ODG) and garcinielliptone FC (GFC), and a polycyclic polyprenylated acylphloroglucinol were isolated from the hexane extract of $P$. insignis seeds. TG1 was effective in healing wounds in rats ${ }^{16}$ and ODG was evaluated regarding toxicological, mutagenic and antioxidant effects in vitro. ${ }^{9}$ GFC presented antioxidant, vasorelaxant and antiparasitic activity. ${ }^{6,15,17}$ In a recent study ${ }^{18}$ of the hydroalcoholic extract of $P$. insignis, containing derivatives of the flavonoid glycosides quercetin and myricetin, showed potential antifungal activity against vaginal Candida species. Considering these previous reports, $P$. insignis has proven to be a valuable source of bioactive compounds.

Anti-inflammatory and antioxidant activities are widely explored in natural products chemistry, mainly due to their importance and benefic effects for humankind. In the past few years, there has been a considerable growth in the number of studies that proves that free radicals and other oxidizing compounds present key roles on the aging process and development, for example, of degenerative, cardiovascular and decline of the immune system diseases. ${ }^{19}$
In the search for novel alternatives for the inflammatory process treatment, natural products have also been highlighted as promising sources. Previous reports ${ }^{20}$ evidence that a large variety of natural products (such as terpenes, alkaloids, tannins, lignans, saponins, coumarins, and flavonoids) can inhibit the synthesis of inflammation chemical mediators. Ethnopharmacological studies ${ }^{21}$ also highlight this potential, since teas and infusions prepared in various regions of the globe present positive results when scientifically tested.

For these and other activities that present, indeed, effects on the organism, it is important to insert the active sample into carrier systems. This type of system can protect the compounds from chemical and physical degradations and, additionally, ensures the performance at the correct time and place. Liquid crystalline systems (LCS) are examples of such carrier systems which can be used as drug delivery system since they can moderate the release of compounds incorporated therein..$^{22}$ This feature is a result of its large internal interfacial area, with different physicochemical characteristics of the external area, which creates two environments with different properties in the formulation, allowing the compartmentalization of both polar and nonpolar drugs..$^{23}$

The search for drug carrier systems that can be used as a vehicle for bioactive molecules is an innovative approach within the chemistry of natural products. Therefore, considering that the shell and seeds from Platonia insignis Mart. fruits are mainly discarded, this study aimed to identify the bioactive compounds in these residues, which could lead to the reuse of the biomass generated and add commercial value to it. For that, the extracts obtained were evaluated for in vitro antioxidant, anti-glycation, and inhibition of $\mathrm{NO}$ activities. Additionally, the in vivo evaluation of the ethyl acetate (EtOAc) shell extract incorporated into a liquid crystalline system was performed for the paw edema protocol. The bioactive compounds were determined in the extracts by different phytochemical analyses, such as high performance liquid chromatography tandem mass spectrometry (HPLC-MS/MS), high performance liquid chromatography-solid phase extraction-nuclear magnetic resonance (HPLC-SPE-NMR). The major compound of EtOAc shell extract, morelloflavone, was isolated to unequivocally determine its structure by NMR technique.

\section{Experimental}

Plant material

The Platonia insignis Mart. fruits were commercially acquired in São Luiz, at the Brazilian state of Maranhão 
in March 2014. The fruits were stored at $-40{ }^{\circ} \mathrm{C}$ until the beginning of this study. The authorization for studying this fruit was conceded by the National System for Management of Genetic Heritage and Associated Traditional Knowledge (SisGen), No. A67DE7A.

\section{Extract preparation}

Fruits were separated into shell, seeds, and pulp. Shell $(280.1 \mathrm{~g})$ and seeds $(104.5 \mathrm{~g})$ were dried at $40{ }^{\circ} \mathrm{C}$ in a circulating air oven and pulverized in liquid nitrogen by a mechanical grinder, while the pulp was discarded. Dried and pulverized material were individually extracted by maceration sequentially with hexane, ethyl acetate, and methanol (98\%, Êxodo Científica, Sumaré, Brazil), for $24 \mathrm{~h}$ in each solvent. The supernatants were concentrated to dryness using a rotatory evaporator at $40{ }^{\circ} \mathrm{C}$ and then lyophilized to remove any water residue, yielding $n$-hexane (6.78 and $50.44 \mathrm{~g}$ ), EtOAc (5.87 and $32.51 \mathrm{~g}$ ), and $\mathrm{MeOH}$ (47.06 and $7.36 \mathrm{~g}$ ) extracts for the shell and seeds, respectively.

\section{Chromatographic procedures}

High performance liquid chromatography-diode array detection (HPLC-DAD)

Analytical HPLC analyses were performed on an HPLC-DAD Prominence Shimadzu ${ }^{\circledR}$, equipped with LC-10AD pump, DGU 20- A $_{3 \mathrm{R}}$ degassing unit, SPD-M10A diode array detector, SIL-10AF automatic injector, and CBM-20A communication module. A Phenomenex ${ }^{\circledR}$ C18-Luna column $(250 \times 4.6 \mathrm{~mm}$ internal diameter (i.d.), $5 \mu \mathrm{m})$ was employed, and the mobile phase consisted in the solvent system $\mathrm{H}_{2} \mathrm{O}$ (A) and $\mathrm{MeOH}$ (B) (HPLC grade, J.T. Baker-Avantor, Radnor, USA), $1.0 \mathrm{~mL} \mathrm{~min}^{-1}$ flow rate, $25^{\circ} \mathrm{C}$, and $20 \mu \mathrm{L}$ injection volume. The dried extracts (seeds and shell extracted with EtOAc and $\mathrm{MeOH}$ ) were solubilized in $\mathrm{MeOH}: \mathrm{H}_{2} \mathrm{O}(8: 2, \mathrm{v} / \mathrm{v})$ at a concentration of $10 \mathrm{mg} \mathrm{mL}^{-1}$, passed through an SPE C18 cartridge for clean-up procedure and filtered in $0.22 \mu \mathrm{m}$ membrane. The gradient employed for the initial analyses consisted of a gradient from 5 to $100 \% \mathrm{~B}$ in $60 \mathrm{~min}$, and chromatograms were registered in the wavelength range of $200-400 \mathrm{~nm}$.

\section{HPLC-MS/MS analysis}

The EtOAc extracts were analyzed in an HPLC Prominence Shimadzu ${ }^{\circledR}$ coupled to a mass spectrometer amaZon SL Bruker Daltonics ${ }^{\circledast}$. The HPLC consisted of an LC-20AD pump, DGU 20- $\mathrm{A}_{3 \mathrm{R}}$ online degassing unit, SPD-M20A diode array detector, CTO-20A column oven, SIL-20AHT automatic injector, and CBM-20 communication module. A Phenomenex ${ }^{\circledR}$ C18-Luna column $(250 \times 4.6 \mathrm{~mm}$ i.d., $5 \mu \mathrm{m})$ was used, and the solvent system consisted of $\mathrm{H}_{2} \mathrm{O}(\mathrm{A})$ and $\mathrm{MeOH}(\mathrm{B})$, both acidified with $0.1 \% \mathrm{v} / \mathrm{v}$ formic acid, at $1.0 \mathrm{~mL} \mathrm{~min}^{-1}$ flow rate, $25{ }^{\circ} \mathrm{C}$ and $2 \mu \mathrm{L}$ injection volume. The dried extracts were solubilized in $\mathrm{MeOH}: \mathrm{H}_{2} \mathrm{O}(8: 2, \mathrm{v} / \mathrm{v})$ at a concentration of $1.0 \mathrm{mg} \mathrm{mL}-1$, centrifuged for $3 \mathrm{~min}$ at $4500 \times \mathrm{g}$ and supernatants were analyzed. The optimized separation conditions employed for the analyses consisted of a linear gradient from 5 to $100 \% \mathrm{~B}$ in $60 \mathrm{~min}$ for the shell and a linear gradient from 5 to $30 \%$ B in 25 min, followed by $30 \%$ $\mathrm{B}$ until $75 \mathrm{~min}$ for the seeds extracts. The mass spectra were obtained separately in both positive and negative mode, in a mass range of 50-1200 Da and applying auto-MS $(n=3)$ mode. The mass spectrometer source parameters were set as follows: capillary voltage at $4.5 \mathrm{~V}$, nitrogen used as the nebulizing and drying gas $\left(50 \mathrm{psi}, 10 \mathrm{~L} \mathrm{~min}^{-1}, 300{ }^{\circ} \mathrm{C}\right)$. The data was processed through Bruker Compass Data Analysis $4.3^{\circledR}$ software.

Semi-preparative HPLC-DAD fractionation of the EtOAc shell crude extract

A portion $(160 \mathrm{mg})$ of the EtOAc extract from P. insignis shell was fractionated by an HPLC-DAD Prominence Shimadzu $^{\circledR}$, equipped with LC-6AD pump, DGU 20-A degassing unit, SPD-M20A diode array detector, and CBM-20A communication module. A semi-preparative Phenomenex ${ }^{\circledR} \mathrm{C} 18$-Luna column $(150 \times 21.2 \mathrm{~mm}$ i.d.; $5 \mu \mathrm{m})$ was employed in this chromatographic step, and the solvent system consisted in $\mathrm{H}_{2} \mathrm{O}(\mathrm{A})$ and $\mathrm{MeOH}(\mathrm{B})$, isocratic mode $60 \% \mathrm{~B}$ in $30 \mathrm{~min}$, a flow rate of $10 \mathrm{~mL} \mathrm{~min}^{-1}$ and injection volume of $1 \mathrm{~mL}$. After collection, the major compound was concentrated in a rotatory evaporator, yielding $5.0 \mathrm{mg}$ of morelloflavone (2).

\section{LC-SPE-NMR fractionation of the EtOAc seeds extract}

The seeds EtOAc extract was submitted to an LC-SPE-NMR fractionation to confirm the information proposed by LC-MS/MS analysis. An Agilent 1260 Infinity system equipped with a quaternary pump, auto-sampler ALS, and diode array detector (DAD VL), connected to a Bruker Spark Prospekt II solid-phase extraction system using $2 \mathrm{~mm}$ Hyspher resin (GP, polydivinyl benzene, particle 5-15 $\mu \mathrm{m})$ cartridge to peak collection was used. A Phenomenex ${ }^{\circledR} \mathrm{C} 18$-Luna column $(250 \times 4.6 \mathrm{~mm}$ i.d., $5 \mu \mathrm{m}$ ) was employed, and the mobile phase consisted of the solvent system $\mathrm{H}_{2} \mathrm{O}(\mathrm{A})$ and $\mathrm{MeOH}(\mathrm{B}), 1.2 \mathrm{~mL} \mathrm{~min}^{-1}$ flow rate and $25{ }^{\circ} \mathrm{C}$. UV detection was performed at $254 \mathrm{~nm}$. The extract was solubilized in $\mathrm{MeOH}: \mathrm{H}_{2} \mathrm{O}(8: 2, \mathrm{v} / \mathrm{v})$ at a concentration of $20 \mathrm{mg} \mathrm{mL}^{-1}$, passed through an SPE C18 cartridge for clean-up procedure and filtered in $0.22 \mu \mathrm{m}$ 
membrane. The separation was done using a linear gradient from 5 to $30 \%$ B in $25 \mathrm{~min}$, followed by an isocratic mode at $30 \%$ B until 75 min. NMR samples were prepared by a Gilson Liquid Handler 215. Then, $20 \mu \mathrm{L}$ of the sample at $20 \mathrm{mg} \mathrm{mL}^{-1}$ was injected 15 times, and the peaks of interest were collected using the multitrapping function considering the peaks retention time: $39.00-40.10 \mathrm{~min}$ for compound $\mathbf{1}, 40.80-42.20 \mathrm{~min}$ for compound $\mathbf{2}$, 53.22-55.22 $\mathrm{min}$ for compound $\mathbf{3}$ and 56.00-58.00 min for compound 4. After completing the analyses, the loaded SPE cartridges were dried with $\mathrm{N}_{2}$ gas, and the adsorbed compounds were eluted using methanol- $d_{4}$ (99.8\% D, Sigma-Aldrich, St. Louis, USA) into $3 \mathrm{~mm}$ NMR tubes. NMR spectra were recorded on the NMR spectrometer described later, with double solvent presaturation suppressing any residual water and methanol signals (pulse program "lc1pnf2"). HyStar software was used for automated trapping control.

\section{Morelloflavone quantification and method validation}

To validate the HPLC-DAD method, the parameters of linearity, precision (intra and inter-day repeatability), limit of detection, limit of quantification, and robustness were evaluated according to the method described by International Council for Harmonisation of Technical Requirements for Pharmaceuticals for Human Use (ICH). ${ }^{24}$ To obtain the analytical curve and linearity study, standard solutions of the previously isolated morelloflavone were used in the concentration range between 0.01 and $0.20 \mathrm{mg} \mathrm{mL}^{-1}$, diluted from a $1 \mathrm{mg} \mathrm{mL}^{-1}$ stock solution. Precision was expressed by the standard deviation of three consecutive injections of the $0.1 \mathrm{mg} \mathrm{mL}^{-1}$ standard solution on three different days. The limits of detection and quantification were calculated considering, respectively, 3.3 and 10 times the ratio between the standard deviation of the linear coefficient (s) and the angular coefficient (S) of the analytical curve.

The method robustness was expressed by the coefficient of variation of three consecutive injections of the $0.1 \mathrm{mg} \mathrm{mL} \mathrm{m}^{-1}$ standard solution and evaluated changing the mobile flow rate from 1.0 to $0.8 \mathrm{~mL} \mathrm{~min}^{-1}$. For morelloflavone quantification in the ethyl acetate extract of $P$. insignis shell, $2.5 \mathrm{mg}$ of extract was solubilized in $1 \mathrm{~mL}$ of $\mathrm{MeOH}: \mathrm{H}_{2} \mathrm{O}(8: 2, \mathrm{v} / \mathrm{v})$. Prior to HPLC injection, the extract was passed through the clean-up procedure in C18 cartridge, as previously described. The extract and calibration curve analyses were performed in triplicate.

\section{NMR analyses}

The ${ }^{1} \mathrm{H}(600 \mathrm{MHz}),{ }^{13} \mathrm{C}(125 \mathrm{MHz})$, correlation spectroscopy (COSY), heteronuclear single quantum correlation (HSQC), and heteronuclear multiple bond correlation (HMBC) NMR spectra were recorded on a Bruker Avance III HD $600 \mathrm{MHz}$ NMR spectrometer equipped with a Triple Inverse TCI 5 mm Cryo-probehead and automated sample changer SampleXpress. Spectra were calibrated considering the residual solvent signals (dimethyl sulfoxide (DMSO- $d_{6}$ ): $\delta 2.50$ and 39.5; $\mathrm{CD}_{3} \mathrm{OD}-d_{4}: \delta 3.31$ and 49.00 ; for ${ }^{1} \mathrm{H}$ and ${ }^{13} \mathrm{C}$, respectively), and tetramethylsilane (TMS) as an internal standard. Both DMSO- $d_{6}$ and $\mathrm{CD}_{3} \mathrm{OD}-d_{4}$ were acquired from SigmaAldrich (St. Louis, USA).

\section{Biological assays}

\section{Antioxidant activity assays}

\section{DPPH' scavenging activity}

The DPPH' (2,2-diphenyl-1-picrylhydrazyl) scavenging activity was employed to determine the extracts possibility to reduce this radical, by applying the method previously described. ${ }^{25}$ Dried extracts were solubilized in EtOH at $4 \mathrm{mg} \mathrm{mL}^{-1}$ (EtOH 99\%, Sigma-Aldrich, St. Louis, USA) and diluted to obtain various concentrations ranging from 0.4 to $100 \mu \mathrm{g} \mathrm{mL}^{-1}$. The assays were performed by adding $35 \mu \mathrm{L}$ of the samples in $215 \mu \mathrm{L}$ of an ethanolic solution of DPPH $\left(100 \mu \mathrm{mol} \mathrm{L}{ }^{-1}\right)$. EtOH was used as negative control and rutin was used as standard. After $30 \mathrm{~min}$ incubation in the dark, the activity was determined spectrophotometrically at $517 \mathrm{~nm}$ in a microplate reader (Synergy2 Multi-Mode, BioTek, Winooski, VT, USA). The DPPH ${ }^{*}$ scavenging activity was calculated following the equation $\mathrm{DPPH}_{\text {scavenging }}^{\cdot}(\%)=\left[\left(\mathrm{Abs}_{517 \mathrm{~nm}}(\right.\right.$ control $)-$ $\mathrm{Abs}_{517 \mathrm{~nm}}($ sample $\left.)\right) / \mathrm{Abs}_{517 \mathrm{~nm}}($ control $\left.)\right] \times 100$, where $\mathrm{Abs}_{517 \mathrm{~nm}}$ (control) and $\mathrm{Abs}_{517 \mathrm{~nm}}$ (sample) are the absorbances at $517 \mathrm{~nm}$ of the control and sample, respectively. The radical scavenging capacity was expressed in $\mathrm{EC}_{50}(50 \%$ effective concentration), which was calculated graphically using the analytical curve in the linear range.

\section{$\mathrm{ABTS}^{*+}$ scavenging capacity}

The ABTS $^{\bullet+}$ [2,20-azino-bis(3-ethylbenzothiazoline6-sulfonic acid)] cation radical scavenging capacity was determined based on a method described by Fraige et $a .^{25}$ Initially, $1 \mathrm{~mL}$ of an ABTS solution at $10 \mathrm{mmol} \mathrm{L}^{-1}$ was mixed with $430 \mu \mathrm{L}$ of ammonium persulfate $\left(8.17 \mathrm{mmol} \mathrm{L}^{-1}\right)$. The cation radical was obtained after holding this mixture in the dark at room temperature for $16 \mathrm{~h}$, and this solution was diluted 60 times. Samples were prepared in concentrations ranging from 0.4 to $100 \mu \mathrm{g} \mathrm{mL}^{-1}$, and $35 \mu \mathrm{L}$ of these solutions were added to $215 \mu \mathrm{L}$ of $\mathrm{ABTS}^{\cdot+}$ solution. EtOH was used as negative 
control and quercetin was used as standard. The mixture was incubated in the dark for $30 \mathrm{~min}$ and the activity was determined spectrophotometrically at $755 \mathrm{~nm}$ in a microplate reader (Synergy2 Multi-Mode, BioTek, Winooski, VT, USA). The ABTS ${ }^{++}$scavenging activity was

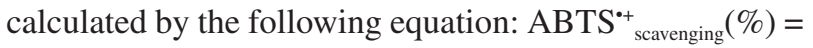
$\left[\left(\mathrm{Abs}_{755 \mathrm{~nm}}\right.\right.$ (control) $-\mathrm{Abs}_{755 \mathrm{~mm}}\left(\mathrm{sample}_{)}\right) / \mathrm{Abs}_{755 \mathrm{~mm}}$ (control)] $\times 100$. The radical scavenging capacity was expressed in terms of $\mathrm{EC}_{50}$, which was calculated graphically using the analytical curve in the linear range.

\section{Peroxyl radical scavenging capacity}

The peroxyl radical (ROO*) scavenging assay was performed based on the fluorescence decay of pyranine (8-hydroxypyrene-1,3,6-trisulfonic acid trisodium salt, a fluorescent probe) when oxidized by peroxyl radicals originated from AAPH [2,20-azobis (2-methylpropionamidine)]. ${ }^{25}$ The experiments were performed by adding $12.5 \mu \mathrm{L}$ of sample solutions in ethanol (ranging from 0.4 to $100 \mu \mathrm{g} \mathrm{mL} \mathrm{L}^{-1}$ ) and $62.5 \mu \mathrm{L}$ of AAPH in phosphate-buffered saline (PBS) medium $\left(40 \mu \mathrm{mol} \mathrm{L}^{-1}\right)$ to $75 \mu \mathrm{L}$ of pyranin $\left(10 \mu \mathrm{mol} \mathrm{L}^{-1}\right)$, also in PBS. The pyranine fluorescence decay was measured at $37{ }^{\circ} \mathrm{C}$ for $90 \mathrm{~min}$ using a plate spectrometer at $485 \mathrm{~nm}\left(\lambda_{\text {excitation }}\right)$ and $528 \mathrm{~nm}$ $\left(\lambda_{\text {emission }}\right)$. Pyranine with AAPH (control 1) and without AAPH (control 2) were used as controls, and gallic acid was used as standard. The $\mathrm{EC}_{50}$ calculation was performed using the equation: radical scavenged $(\%)=[($ Sample Area Control Area 2) / (Control Area 1 - Control Area 2)] × 100 .

\section{Anti-glycation activity}

The anti-glycation activity assay was performed using the bovine albumin (BSA) and methylglyoxal (MGO) method, as described by Lunceford and Gugliucci, ${ }^{26}$ with some modifications. ${ }^{25}$ A solution of BSA $\left(1 \mathrm{mg} \mathrm{mL}^{-1}\right)$ in phosphate buffer $\left(10 \mathrm{mg} \mathrm{mL}^{-1}, \mathrm{pH}\right.$ 7.4) containing $150 \mathrm{mmol} \mathrm{L}^{-1} \mathrm{NaCl}$ was initially prepared. The MGO $\left(5 \mathrm{mmol} \mathrm{L}^{-1}\right.$ ) and the EtOAc and $\mathrm{MeOH}$ extracts (solubilized in 1:1 DMSO: $\mathrm{H}_{2} \mathrm{O}$ to reach $150 \mu \mathrm{g} \mathrm{mL}^{-1}$ ) were added to the BSA solution and then incubated for $72 \mathrm{~h}$ at $37^{\circ} \mathrm{C}$ under $150 \mathrm{rpm}$ shaking. Aminoguanidine $\left(10 \mathrm{mmol} \mathrm{L}^{-1}\right)$ was used as standard and the samples were incubated in the presence and absence of MGO to have the intrinsic fluorescence of each sample. After the incubation period, the fluorescence of the samples was measured using a plate spectrometer at $370 \mathrm{~nm}\left(\lambda_{\text {excitation }}\right)$ and $440 \mathrm{~nm}\left(\lambda_{\text {emission }}\right)$. For the calculation of inhibition, the equation was used: Inhibition of AGEs formation $(\%)=$ $\left[\left(\mathrm{FL}_{\mathrm{CN}}-\mathrm{FL}_{\mathrm{bCN}}\right)-\left(\mathrm{FL}_{\mathrm{S}}-\mathrm{FL}_{\mathrm{bS}}\right)\right] /\left(\mathrm{FL}_{\mathrm{CN}}-\mathrm{FL}_{\mathrm{bCN}}\right)$; where $\mathrm{FL}_{\mathrm{CN}}$ and $\mathrm{FL}_{\mathrm{bCN}}$ are the fluorescence intensities of the negative control mixture and its blank, respectively; and $\mathrm{FL}_{\mathrm{S}}$ and $\mathrm{FL}_{\mathrm{bS}}$ are the fluorescence intensities of the extract and its blank, respectively.

\section{In vitro inhibition of NO production assay}

\section{Cell culture}

The cell line RAW 264.7, derived from a leukemic mouse monocyte-macrophage line American Type Culture Collection (ATCC)/TIB-71, was acquired from the Rio de Janeiro Cell Bank (BCRJ). Cells were maintained at $37^{\circ} \mathrm{C}$ in a humidified incubator with $5.0 \% \mathrm{CO}_{2}$, in cells culture flasks in Dulbecco's modified Eagle medium (DMEM, Lonza, Basel, Switzerland), using as supplements 10\% of heat-inactivated fetal bovine serum (FBS, Gibco, Waltham, USA) and gentamicin (1:1000, Gibco, Waltham, USA).

\section{Cytotoxicity assay}

Cells were initially seeded in 96 -well plates $\left(1 \times 10^{5} \mathrm{well}^{-1}\right)$ in a final volume of $200 \mu \mathrm{L}$ and incubated for $18 \mathrm{~h}$. After this time, the medium was removed, cells were treated during 90 min with the EtOAc shell extract of P. insignis (solubilized in DMSO and diluted with DMEM to reach concentrations from 0.78 to $25.0 \mu \mathrm{g} \mathrm{mL}{ }^{-1}$ ), and then incubated with lipopolysaccharide (LPS, $100 \mathrm{ng} \mathrm{mL}^{-1}$, Sigma-Aldrich, St. Louis, USA) under $5.0 \%$ of $\mathrm{CO}_{2}$ for $18 \mathrm{~h}$ at $37^{\circ} \mathrm{C}$. Cytotoxic activity was determined by the MTT (3-[4,5-dimethylthiazol-2-yl]-2,5-diphenyltetrazolium bromide) method, in which the new supernatant was collected for NO determination, and the macrophages were incubated with MTT at $5 \mathrm{mg} \mathrm{mL}-1$ in PBS for $3 \mathrm{~h}$ at $37^{\circ} \mathrm{C}$. Sodium dodecyl sulfate (SDS 20\%, $0.01 \mathrm{~mol} \mathrm{~L}^{-1} \mathrm{HCl}$ ) was added to dissolve formazan crystals and then absorbance was measured at $595 \mathrm{~nm}$ (BioTek-Synergy H1).

\section{Quantification of nitrite}

The measurement of the nitrite concentration was performed by the Griess method from cell culture supernatant, in which $100 \mu \mathrm{L}$ of a solution consisting of $0.1 \%$ NEED (naphthyl-ethylenediamine dihydrochloride) solution and $1 \%$ sulfanilamide in $\mathrm{H}_{3} \mathrm{PO}_{4}(\mathrm{v} / \mathrm{v})$, both from Sigma-Aldrich (St. Louis, USA), were mixed to $100 \mu \mathrm{L}$ of cell supernatant, and the nitrite concentration was determined by measuring the absorbance at $540 \mathrm{~nm}$ (BioTek-Synergy H1), limit of detection of 0.06 to $200 \mu \mathrm{M}$.

Preparation and polarized light microscopy analysis of the liquid crystalline system

The liquid crystalline system used to incorporate the EtOAc extract of the shell to perform the in vivo anti- 
inflammatory was a liquid crystalline system prepared from one of the points in the ternary diagram obtained previously. ${ }^{27,28}$ This LCS was composed of $40 \%$ oleic acid as oily phase, $30 \%$ Procety $^{\circledR}$ as the surfactant, and $30 \%$ high-purity water as the aqueous phase. EtOAc extract was loaded into the oily phase, reaching $4 \mathrm{mg}$ of extract per $10 \mathrm{~g}$ of LCS.

The unloaded and EtOAc extract-loaded LCSs were analyzed by polarized light microscopy (PLM) using a Motic ${ }^{\circledR}$ Type 102M Optical Microscope (Motic ${ }^{\circledR}$, Xiamen, Fujian, China) optical microscope by placing a drop of each formulation under a coverslip. The analysis was performed at room temperature $\left(25^{\circ} \mathrm{C}\right)$ and images were acquired at $40 \times$ magnification.

\section{In vivo anti-inflammatory assay}

The in vivo study was carried out after the Committee on Ethics in the Use of Animals (CEUA) approval in the Faculty of Pharmaceutical Sciences of Araraquara, Unesp (Protocol No. 18/2017). The paw edema protocol described by Vinegar et al. ${ }^{29}$ was used, which proposes the induction of paw edema in the animal using dexamethasone as a drug and evaluation of the decrease of this process after the administration of the samples analyzed. Male mice of Swiss lineage with a mean weight of $35 \mathrm{~g}$ were subdivided into seven groups, with seven animals per group: group I: untreated (negative control); group II: treated with topic dexamethasone at $1 \mathrm{mg} \mathrm{g}^{-1}$ (positive control); group III: treated only with $P$. insignis EtOAc shell extract (400 $\mu \mathrm{g} \mathrm{mL}^{-1}$ ) solubilized in EtOH: $\mathrm{H}_{2} \mathrm{O} 95: 5$ (v/v); group IV: treated with formulation 1 (F1), at $400 \mu \mathrm{g} \mathrm{g} \mathrm{g}^{-1}$, LCS without extract; group V: treated with $P$. insignis EtOAc shell extract incorporated in formulation F1 at $400 \mu \mathrm{g} \mathrm{g}^{-1}$; group VI: treated with formulation 2 (F2), a carboxymethyl cellulose (CMC) gel without extract; and group VII: treated with $P$. insignis EtOAc shell extract incorporated in formulation $\mathrm{F} 2$ at $400 \mu \mathrm{g} \mathrm{g}^{-1}$. F1 formulation refers to the drug carrier system developed for the incorporation of the fruit shell EtOAc extract, while F2 formulation is a commonly used gel consisting of $\mathrm{H}_{2} \mathrm{O}: \mathrm{EtOH}$ 95:5 (v/v) mixture and $2 \%(\mathrm{~m} / \mathrm{m})$ carboxymethylcellulose.

The paw edema was induced by intraplantar injection of $100 \mu \mathrm{L}$ of $1 \%(\mathrm{~m} / \mathrm{m}) \lambda$-carrageenan into the mouse's paw. One hour later, dexamethasone or test formulations (100 mg) were applied to the animal's paw, and after 4 and $6 \mathrm{~h}$ of $\lambda$-carrageenan administration, the leg thickness was measured (in mm) using a digital micrometer. The percent inhibition of paw edema was calculated according to the equation: Inhibition $(\%)=\left(E_{c}-E_{t}\right) / E_{t} \times 100$, in which $E_{c}$ is the paw edema of the control group and $\mathrm{E}_{\mathrm{t}}$ is the edema of the treated group. The mean and standard deviation of the thickness were calculated for each group. The two-way analysis of variance (ANOVA) was performed, followed by Tukey's post-test. The difference between the mean edema of the treated animals and the control group was considered significant at $p<0.05$.

\section{Results and Discussion}

\section{Chromatographic investigation of the extracts}

The extraction procedure followed (using solvents with different polarities) was chosen to ensure the extraction of compounds with a wide range of polarities. This procedure would already result in a preliminary separation of these compounds by the different solvents used. Ethyl acetate (EtOAc) and methanolic $(\mathrm{MeOH})$ extracts obtained from $P$. insignis shell and seeds were analyzed by HPLC-DAD for a preliminary chemical investigation using optimized chromatographic methods, which chromatograms are shown in the Supplementary Information (SI, Figure S1).

\section{Shell}

The chromatograms obtained for the EtOAc shell extract indicated a selective extraction of a specific compound. This extract was then subjected to semipreparative chromatography for isolation of the major compound, yielding compound 2 . This compound was identified as morelloflavone (Figure 1) by the comparison with data of literature ${ }^{30,31}$ of 1D and 2D NMR analyses and fragmentation pattern by LC-MS/MS (SI section).

The assignments of the main ${ }^{1} \mathrm{H}$ and ${ }^{13} \mathrm{C}$ NMR chemical shifts of compound $\mathbf{2}(\mathbf{2} \mathbf{a}+\mathbf{2} \mathbf{b}$ rotamers $)$, in $\mathrm{CD}_{3} \mathrm{OD}-d_{4}$, were achieved with the assistance of gHSQC and gHMBC experiments (NMR spectra can be found in the SI section, Figures S2-S4) and are shown in the Table S1 (SI section). Although long-range heteronuclear correlations were not observed between H-2 or H-3 with C-8", partly due to the pre-saturation of the water signal which resulted in the concomitant irradiation of $\mathrm{H}-3$, the signals attributed to C-8" ( $\delta 102.0$ in both rotamers) evidenced that the flavonoid units were linked through C-3 and C-8". Further evidence for the chemical structure established for $\mathbf{2}$ was provided by the molar ratio (1:0.35) observed between the rotamers $\mathbf{2 a}$ and $\mathbf{2 b}{ }^{32}$ The relative configuration of $\mathbf{2}$ was determined as shown in Figure 1, based mainly on the diaxial coupling constant value ( $\mathrm{J}$ ca. $12 \mathrm{~Hz}$ ) between $\mathrm{H}-2$ and $\mathrm{H}-3$, which was observed when 2 was analyzed in DMSO- $d_{6}$.

Morelloflavone is a biflavonoid commonly found in Garcinia species (also from the Clusiaceae family). ${ }^{33}$ Many studies regarding this compound have revealed important 
<smiles>O=C1CC(c2ccc(O)c(O)c2)Oc2c(O)cc(O)c(C3C(=O)c4c(O)cc(O)cc4OC3c3ccc(O)cc3)c21</smiles>

1

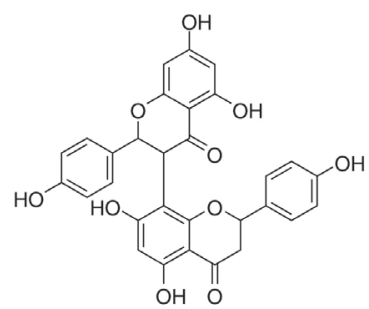

3<smiles>O=C1c2c(O)cc(O)cc2O[C@H](c2ccc(O)cc2)[C@H]1c1c(O)cc(O)c2c(=O)cc(-c3ccc(O)c(O)c3)oc12</smiles><smiles>O=C1c2c(O)cc(O)cc2OC(c2ccc(O)cc2)C1c1c(O)cc(O)c2c(=O)cc(-c3ccc(O)cc3)oc12</smiles>

4
Figure 1. Main compounds identified in P. insignis EtOAc extracts: (1) GB-2a; (2) morelloflavone; (3) GB-1a; (4) volkensiflavone. Morelloflavone was isolated from the $P$. insignis shell EtOAc extract, and its relative stereochemistry was determined by NMR.

bioactivities such as tyrosinase inhibitor, ${ }^{30}$ proteasomeinhibitory activity ${ }^{34}$ promotion of secretory phospholipase $\mathrm{A}_{2}\left(\mathrm{PLA}_{2}\right)$ inhibition, ${ }^{35}$ anti-inflammatory,${ }^{35}$ activity against low density lipoprotein (LDL) peroxidation, ${ }^{36}$ antitumorpromoting activity, ${ }^{37,38}$ and potent and selective anti-HIV (human immunodeficiency virus) activity. ${ }^{39}$

Morelloflavone (96\% purity, estimated by HPLC-DAD) was quantified in P. insignis EtOAc shell extract and the developed method showed to be linear in the concentration range from 0.01 to $0.20 \mathrm{mg} \mathrm{mL}^{-1}$, presenting a coefficient of correlation $\left(\mathrm{r}^{2}\right)$ of 0.9937 . For the precision determination, the values for intra-day and between 3 different days (inter-day) repeatabilities were calculated for the retention time and peak area at the $0.1 \mathrm{mg} \mathrm{mL}^{-1}$ concentration and were expressed by the coefficient of variation $(\mathrm{CV}$, in \%). Considering each day repeatability, the $\mathrm{CV}$ ranged from 0.92 to $2.16 \%$ for the retention time and from 1.17 to $7.72 \%$ for peak area; for the inter-day repeatability, these values were 2.97 and $4.37 \%$ for retention time and peak area, respectively.

The method robustness was evaluated by changing the mobile flow rate from 1.0 to $0.8 \mathrm{~mL} \mathrm{~min}{ }^{-1}$, and the coefficient of variation for retention time and peak area was 0.33 and $0.39 \%$, respectively; therefore, the method can be considered accurate and robust.

The limits of detection and quantification were, respectively, 0.01 and $0.04 \mathrm{mg} \mathrm{mL}^{-1}$. The morelloflavone concentration found by the analytical curve in the EtOAc extract was $0.085 \pm 0.006 \mathrm{mg} \mathrm{mL}^{-1}(\mathrm{CV}=6.96 \%)$, which consists of $340 \mathrm{mg} \mathrm{g}^{-1}$ of the extract. This result shows that bacuri is a very important source of morelloflavone.

\section{Seeds}

To also investigate the seeds extract, LC-MS/MS analyses were also performed to identify the chemical compounds present in this extract (Figure 1). Figure 2 presents the base peak chromatogram (BPC) obtained for the EtOAc seeds extract in negative mode, and the peaks identified are described in Table 1. The compounds' identification was based on the deprotonated molecules, fragmentation patterns, and comparison with data from the literature. ${ }^{40}$ The $\mathrm{MS}^{2}$ and $\mathrm{MS}^{3}$ spectra described in Table 1 can also be found in Figures S5-S8 (SI section), and the proposed fragments

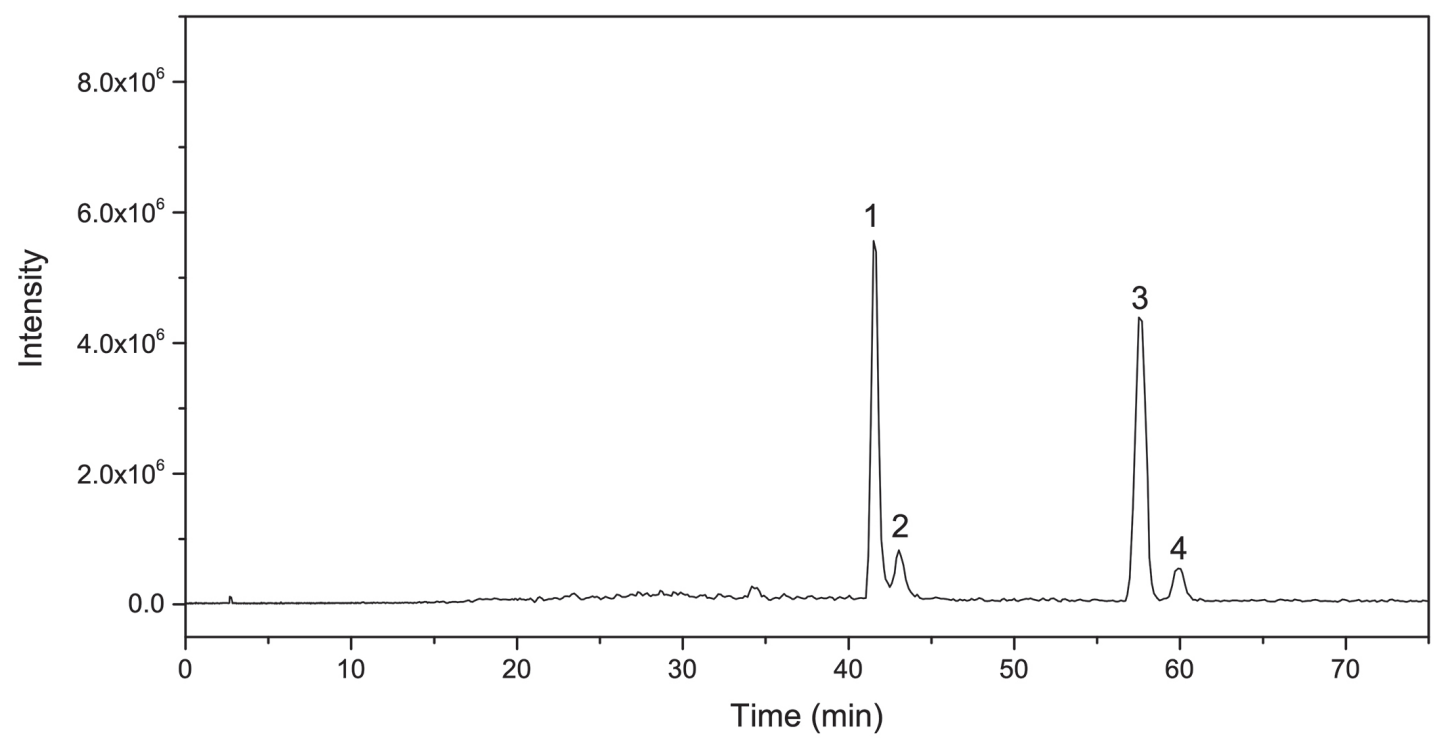

Figure 2. Base peak chromatogram (BPC) of the P. insignis EtOAc seeds extract. Peak numbers are identified in Table 1. Experimental conditions are described in the Experimental section. 
Table 1. Peak number according to Figure 2, retention time $\left(\mathrm{t}_{\mathrm{R}}\right),[\mathrm{M}-\mathrm{H}]^{-}$ion, $\mathrm{MS}^{\mathrm{n}}$ fragments, and compounds tentatively identified from the P. insignis EtOAc seeds extract

\begin{tabular}{|c|c|c|c|c|}
\hline Peak & $\mathrm{t}_{\mathrm{R}} / \min$ & {$[\mathrm{M}-\mathrm{H}]^{-}$} & $\mathrm{MS}^{\mathrm{n}}$ fragments / $\%$ abundance & Compound \\
\hline 1 & 41.5 & 557 & $\begin{array}{c}\mathrm{MS}^{2}(557): 451(2), 431(100) \\
\mathrm{MS}^{3}(557 \rightarrow 431): 321(8), 295(100)\end{array}$ & GB-2a \\
\hline 2 & 43.0 & 555 & $\begin{aligned} & \operatorname{MS}^{2}(555): 403(3), 429(100) \\
M^{3}(555 \rightarrow & 429): 429(100), 401(13), 357(4), 295 \text { (4) }\end{aligned}$ & morelloflavone \\
\hline 3 & 57.5 & 541 & $\begin{array}{c}\operatorname{MS}^{2}(541): 447(20), 415(100) \\
\operatorname{MS}^{3}(541 \rightarrow 415): 321(40), 295(100)\end{array}$ & GB-1a \\
\hline 4 & 59.9 & 539 & $\begin{array}{c}\operatorname{MS}^{2}(539): 445(20), 433(20), 413(100) \\
\operatorname{MS}^{3}(539 \rightarrow 413): 413(100), 385(40), 295(1)\end{array}$ & volkensiflavone \\
\hline
\end{tabular}

formed in this analysis can be found in Figure S9 (SI section). Additionally, the UV spectra obtained for each compound is shown in Figure S10 (SI section).

The major compounds ( $\mathbf{1}$ and $\mathbf{3}, \mathrm{GB}-2 \mathrm{a}$ and GB-1a) presented a very similar fragmentation pattern. Peaks of compounds 1 (at $m / z 557[\mathrm{M}-\mathbf{H}]^{-}$) and 3 (at $m / z 541$ $[\mathrm{M}-\mathrm{H}]^{-}$) formed the major $\mathrm{MS}^{2}$ fragments at $\mathrm{m} / \mathrm{z} 431$ and 415 , respectively, consistent with the loss of $\mathrm{a}_{6} \mathrm{H}_{6} \mathrm{O}_{3}$ group (126 Da) resulted from the biflavonoid $\mathrm{C}$ ring cleavage. The $\mathrm{MS}^{3}$ fragment observed at $\mathrm{m} / \mathrm{z} 295$ could be related to the loss of a $\mathrm{C}_{8} \mathrm{H}_{8} \mathrm{O}_{2}$ group (136 Da) by a retro Diels-Alder C ring-opening reaction. Additionally, an $\mathrm{MS}^{3}$ fragment at $\mathrm{m} / \mathrm{z} 321$ was observed for both compounds, which could be explained by the $\mathrm{B}$ ring flavonoid cleavage, resulting in the loss of a $\mathrm{C}_{6} \mathrm{H}_{6} \mathrm{O}_{2}$ group (110 Da) for compound $\mathbf{1}$, and $\mathrm{C}_{6} \mathrm{H}_{6} \mathrm{O}$ (94 Da) for compound 3 .

Peaks of compounds 2 (at $\mathrm{m} / \mathrm{z}, 555)$ and 4 (at $\mathrm{m} / \mathrm{z}$ 539) could be identified as the minor compounds in this extract: morelloflavone and volkensiflavone, respectively. For both compounds, a loss of a $\mathrm{C}_{6} \mathrm{H}_{6} \mathrm{O}_{3}$ group (126 Da) from the biflavonoid $\mathrm{C}$ ring cleavage was observed, forming the fragments at $\mathrm{m} / \mathrm{z}, 429$ for compound 2 and $\mathrm{m} / \mathrm{z} 413$ for compound 4. The $\mathrm{MS}^{3}$ spectra also revealed the $\mathrm{CO}$ loss (28 Da) and retro-Diels-Alder $\mathrm{C}$ ring-opening reaction, forming $\mathrm{MS}^{3}$ ions at $\mathrm{m} / \mathrm{z}, 401$ and 295 for morelloflavone, and $m / z 385$ and 279 for volkensiflavone.

Considering that the attempts to isolate the compounds present in the seeds were unsuccessful since the peaks coeluted and the time of the analysis would be very long for isolation purposes, a micro-fractionation was performed by LC-SPE-NMR approach to confirm the compounds proposed by LC-MS/MS. The procedure consisted of a fractionation performed in the analytical scale in which SPE collectors are connected to the chromatograph.

The obtained chromatogram is shown at the Supplementary Information (Figure S11). Each one of the four peaks were collected in micro SPE C18 cartridges, which provided enough mass to perform ${ }^{1} \mathrm{H}$ NMR experiments (Figures S12 and S13, SI section).
Bidimensional experiments were not possible to obtain due to the low mass amount collected.

The ${ }^{1} \mathrm{H}$ NMR spectrum of $\mathbf{4}$ resembled the one obtained from 2 (isolated from bacuri's shell), the only significant difference being the absence of the signals assigned to H-2"' (2a: $\delta 7.35 \mathrm{~d}, J 1.7 \mathrm{~Hz}, 1 \mathrm{H}), \mathrm{H}-5$ " $(2 \mathbf{2 a}: \delta 6.93 \mathrm{~d}$, $J 8.4 \mathrm{~Hz}, 1 \mathrm{H})$, and H-6" ' $(2 \mathrm{a}: \delta 7.30 \mathrm{~d}, J 8.4$ and $1.7 \mathrm{~Hz}$, $1 \mathrm{H})$ of 2 , which were replaced by two doublets at $\delta 7.75$ $(J 8.4 \mathrm{~Hz}, 2 \mathrm{H})$ and $6.94(J 8.4 \mathrm{~Hz}, 2 \mathrm{H})$, a characteristic of the apigenin subunit. Similarly, compound $\mathbf{4}$ has also been shown to be a mixture of rotamers, as evidenced by the signal at $\delta 7.61(\mathrm{~d}, J 8.5 \mathrm{~Hz})$. Based mainly on this comparative analysis and comparison with the literature, ${ }^{32,41}$ an interflavonoid linkage C-3 $\rightarrow$ C 8 " was also suggested to occur in 4 . This inference was supported by the mass fragmentation pattern observed for $\mathbf{4}$, and therefore it was identified as volkensiflavone.

${ }^{1} \mathrm{H}$ NMR spectrometric data corroborated with the proposed chemical structures for $\mathbf{1}$ and $\mathbf{3}$ based on MS/MS analyses. Both ${ }^{1} \mathrm{H}$ NMR spectra showed two sets of signals between 7.2-6.6 ppm and 6.0-5.1 ppm, whose values of chemical shifts were compatible with those previously reported for GB-1a and GB-2a. ${ }^{41}$ In these same spectra, signals between 3.0-2.4 ppm were present as well, thus reinforcing the flavanone nature of the structural subunits of $\mathbf{1}$ and $\mathbf{3}$, also proposed by MS/MS analyses.

\section{Bioassays results}

\section{Antioxidant assays}

All extracts obtained were evaluated regarding their antioxidant capacity using three different in vitro scavenging assays ( $\mathrm{DPPH}^{\circ}, \mathrm{ABTS}^{-+}$and $\mathrm{ROO}^{\circ}$ ) to observe the antioxidant capacities in different conditions. The $\mathrm{EC}_{50}$ results obtained for each assay are shown in Table 2. $\mathrm{DPPH}^{\circ}$ and $\mathrm{ABTS}^{\circ+}$ assays are based on an electron transfer causing the reduction of a colored oxidant agent in the organic and aqueous medium, respectively, and the ROO` assay is based on a hydrogen atom transfer in which there is a competition 
Table 2. $\mathrm{EC}_{50}$ values obtained for the $\mathrm{DPPH}^{*}, \mathrm{ABTS}^{*}$ and $\mathrm{ROO}{ }^{*}$ antioxidant activity assays of the $P$. insignis extracts and standard compounds

\begin{tabular}{|c|c|c|c|c|}
\hline Assay & Shell & $\mathrm{EC}_{50} /\left(\mu \mathrm{g} \mathrm{mL}^{-1}\right)$ & Seed & $\mathrm{EC}_{50} /\left(\mu \mathrm{g} \mathrm{mL}^{-1}\right)$ \\
\hline \multirow{4}{*}{$\mathrm{DPPH}^{\bullet}$} & Hex & $>100$ & Hex & $>100$ \\
\hline & EtOAc & $10.50 \pm 0.03$ & EtOAc & $33.03 \pm 0.10$ \\
\hline & $\mathrm{MeOH}$ & $>100$ & $\mathrm{MeOH}$ & $78.00 \pm 0.09$ \\
\hline & rutin & $2.13 \pm 0.03$ & rutin & $2.98 \pm 0.08$ \\
\hline \multirow{4}{*}{$\mathrm{ABTS}^{*+}$} & Hex & $>100$ & Hex & $>100$ \\
\hline & EtOAc & $8.10 \pm 0.09$ & EtOAc & $30.00 \pm 0.12$ \\
\hline & $\mathrm{MeOH}$ & $>100$ & $\mathrm{MeOH}$ & $75.90 \pm 0.03$ \\
\hline & quercetin & $3.10 \pm 0.03$ & quercetin & $4.00 \pm 0.10$ \\
\hline \multirow{4}{*}{$\mathrm{ROO}^{\circ}$} & Hex & $>100$ & Hex & $>100$ \\
\hline & EtOAc & $7.99 \pm 0.09$ & EtOAc & $>100$ \\
\hline & $\mathrm{MeOH}$ & $>100$ & $\mathrm{MeOH}$ & $>100$ \\
\hline & gallic acid & $1.93 \pm 0.03$ & gallic acid & $2.15 \pm 0.60$ \\
\hline
\end{tabular}

$\mathrm{EC}_{50}: 50 \%$ effective concentration; DPPH': 2,2-diphenyl-1-picrylhydrazyl; ABTS ${ }^{*}:$ 2,20-azino-bis(3-ethylbenzothiazoline-6-sulfonic acid); ROO’: peroxyl radical.

between antioxidants agents and substrates for the peroxyl radicals thermally formed. ${ }^{42}$

The results obtained evidenced that all $P$. insignis hexane extracts were not able to scavenge the free radicals formed in these assays, presenting a very elevated $\mathrm{EC}_{50}$ value, which could be attributed to the high content of nonpolar compounds present in these extracts. For this reason, the hexane extracts were not chemically investigated. The methanolic extracts obtained from bacuri's shell also presented elevated $\mathrm{EC}_{50}$ values, indicating that even though polar compounds were extracted, a high amount of sugars could have also been extracted employing this organic solvent. For the seeds methanolic extracts, $\mathrm{EC}_{50}$ values ranging from $>100$ to $76 \mu \mathrm{g} \mathrm{mL} \mathrm{m}^{-1}$ were obtained, showing low antioxidant activities, probably also due to the presence of sugars. The ethyl acetate extracts obtained from the shell extract exhibited high antioxidant activities, with low $\mathrm{EC}_{50}$ values of $10.5,8.1$ and $8.0 \mu \mathrm{g} \mathrm{mL}^{-1}$ for the $\mathrm{DPPH}^{\circ}, \mathrm{ABTS}^{\circ+}$ and ROO' assays, respectively, comparable to the standards used in this research. For the seeds ethyl acetate extracts, the peroxyl radical assay did not show antioxidant activity, while for the $\mathrm{DPPH}^{*}$ and $\mathrm{ABTS}^{\cdot+}$ methods, moderate activities were observed.

Antioxidant activities regarding $P$. insignis fruit extracts have already been described before for its pulp ${ }^{11}$ and seeds,${ }^{14}$ whose activities were attributed to the presence of phenolic compounds. Costa Junior et al. ${ }^{14}$ reported that ethyl acetate and dichloromethane fractions from $P$. insignis seeds present antioxidant activity in vitro (measured by $\mathrm{ABTS}^{++}$and $\mathrm{DPPH}^{*}$ assays), and in vivo (measured by protective effects against the cytotoxicity induced by $\mathrm{H}_{2} \mathrm{O}_{2}$ in $S$. cerevisiae strains). In addition to the polyphenols, they attributed the high antioxidant activity to the xanthones alpha- and gamma-mangostin present in these fractions. ${ }^{14}$ Considering that the biflavonoid morelloflavone is the major compound present in P. insignis EtOAc shell extract, it was possible to attribute the antioxidant bioactivities observed to this compound, since reports for the high antioxidant activity of this biflavonoid has already been reported. ${ }^{43}$ The flavonoid class presents, in general, important antioxidant properties due to the delocalization of the free radical formed. The ethyl acetate seeds extract also presented considerable antioxidant activities, however, the lower activity when compared to the shell extract can be related to the presence of major compounds GB-1a and GB-2a, which do not present a double bond between atoms $\mathrm{C}_{2}$ " and $\mathrm{C}_{3}$ ", important for the stabilization of the free radicals formed. ${ }^{44}$

\section{Anti-glycation assay}

To evaluate the anti-glycation properties of the EtOAc and $\mathrm{MeOH} P$. insignis extracts, their advanced glycation end products (AGEs) formation inhibition was determined using a BSA/MGO system, and the results are shown in the Supplementary Information (Figure S14) as the percentage of inhibition of the glycation reaction.

The EtOAc extract obtained from the shell inhibited about $80 \%$ of the AGEs formation during this assay at the concentration employed $\left(150 \mu \mathrm{g} \mathrm{mL}^{-1}\right)$. This high activity was expected since compounds with high antioxidant properties can present potentialized anti-glycant effects, ${ }^{26}$ and correlations between phenolic compounds and antiglycation activity have already been reported.$^{38}$ On the other hand, the seeds extract presented moderate to low anti- 
glycation activity, ranging from 26 to $39 \%$ AGEs formation inhibition at the concentration employed $\left(150 \mu \mathrm{g} \mathrm{mL}^{-1}\right)$.

Additionally, to the formation of free radicals, glycation reactions also occur naturally in the human body through the enzymatic addition of reducing sugars in proteins. The major problem associated with this phenomenon is the product generated, called AGEs, which are highly reactive and can lead to complex reactions of dehydration, oxidation, and fragmentation, which are very harmful to the human body. ${ }^{45}$ The formation of AGEs is associated with the pathogenic process of diabetes and skin aging. Anti-glycation results have already been described for Garcinia species (also from Clusiaceae family), such as Garcinia semseii, G. volkensii ${ }^{46}$ and $G$. mangostana, ${ }^{47}$ in which the activities could be related to the presence of benzophenones, biflavonoids, and xanthones in the extracts, respectively. Previous studies ${ }^{11}$ also demonstrate the high $\alpha$-glycosidase inhibitory capacity of the hydroalcoholic pulp extract of $P$. insignis, indicating this is a potential source of glucose-lowering compounds, which are important for the glycemic control in type 2 diabetes.

Considering that the major compound present in the most active extract is morelloflavone, it is most likely that the anti-glycant activity observed is related to the presence of this compound in the sample. Morelloflavone has already been described ${ }^{46}$ for many bioactivities, including anti-glycation activity. A subfraction of the ethyl acetate fraction of $P$. insignis containing a mixture of the biflavonoids volkensiflavone and morelloflavone showed promising results as an adjuvant in the antibiotic therapy of multidrug resistant $S$. aureus strains overexpressing efflux pumps. ${ }^{48}$

\section{In vitro inhibitory effects on NO production}

Considering the high antioxidant and anti-glycation activities observed for the EtOAc extract obtained from the shell of $P$. insignis fruit, and due to the extract simplicity (showing the selective extraction of morelloflavone), this extract was also evaluated for their inhibitory effects on NO production in LPS-activated RAW 264.7 macrophages.

Therefore, RAW 264.7 cells were treated with different extract concentrations $\left(0.78-25.0 \mu \mathrm{g} \mathrm{mL}^{-1}\right)$ for $90 \mathrm{~min}$, in which only concentrations 0.78 and $1.56 \mu \mathrm{g} \mathrm{mL}^{-1}$ were considered promising since they presented cell viability $\geq 90 \%$ (Figure $3 \mathrm{a}$ ). The other concentrations tested were discarded due to the cytotoxic results that could provide false positives. Considering the low toxicity of these samples, RAW 264.7 macrophages were stimulated with an inflammatory compound, LPS (100 $\mathrm{ng} \mathrm{mL}^{-1}$ ) for $18 \mathrm{~h}$, and the nitrite concentration was determined in cell supernatant by the Griess reagent.

\section{P. insignis shell EtOAc}

\section{$P$. insignis shell EtOAc}

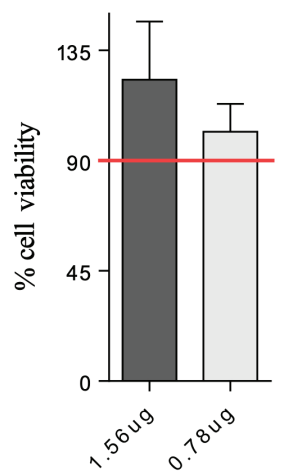

(a)

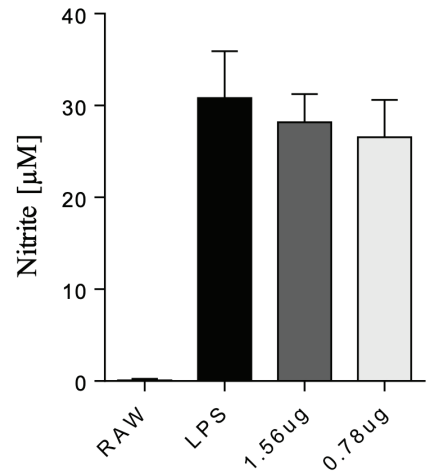

(b)
Figure 3. (a) Cytotoxicity evaluation of $P$. insignis EtOAc shell extract. The red line indicates $90 \%$ cell viability; (b) percentage of inhibition of nitrite $\left(\mathrm{NO}_{2}^{-}\right)$production of EtOAc extract at the concentrations with cell viability $\geq 90 \%$, determined by the Griess reagent. Results indicate the mean \pm SD of three independent experiments performed in quadruplicate for each condition.

As observed in Figure 3b, the incubation with LPS led to an increase in the $\mathrm{NO}_{2}^{-}$production when compared to the cells cultured only with medium (negative control). There was no difference in nitrite production when compared to LPS-stimulated macrophages in the presence or absence of $P$. insignis EtOAc shell extract. The MTT viability test was calculated based on the viability found in cells treated with LPS as $100 \%$ (positive control).

Previous studies correlate morelloflavone (obtained from Garcinia genus) to anti-inflammatory activities, both by in vivo ${ }^{49}$ and in vitro approaches. ${ }^{50}$ However, as observed by these results, the samples were not able to reduce the NO production in cells.

Inflammation is a biological response of the immune system, and the inflammatory response is divided into three phases. The first phase, an acute, transient phase, is characterized by local vasodilatation and increased capillary permeability. The second phase, a sub-acute phase, is characterized by the infiltration of leukocytes and phagocytic cells. And the third and last phase, a chronic proliferative one, in which tissue degeneration and fibrosis occur. In the inflammatory process, many chemical mediators are divided into two groups: those that are derived from plasma and the ones derived from cells. ${ }^{51}$

In this study, the quantified NO (which is one of the chemical mediators, derived from cells) was analyzed. Then, although the samples were not able to reduce the production of NO, they might act as anti-inflammatory agents in other chemical mediators. Furthermore, occasionally, the in vitro assay results cannot be correlated with the in vivo assays as this experiment does not mimic the biological environment of an animal entirely. ${ }^{52}$ 
Preparation and polarized light microscopy analysis of the liquid crystalline system

Due to the important biological activities presented by the in vitro assays for the $P$. insignis EtOAc shell extract and the almost exclusive presence of an interesting biflavonoid (morelloflavone), this extract was selected for the incorporation into the drug delivery system and analysis of its potential anti-inflammatory activity in vivo. The chosen drug delivery system was a liquid-crystalline system, which could be identified through polarized light microscopy, as observed in the Figure S15 (SI section). Structures in the form of stretch marks were observed, which are important features of the hexagonal liquid-crystalline mesophase chosen for the developed system. ${ }^{53}$ This type of mesophase is one of the most common in formulations of topical use due to the ability to protect the compounds incorporated from thermal and photodegradation, in addition to promoting the retention of water in the stratum corneum, which increases the skin permeation. ${ }^{54,55}$

\section{In vivo anti-inflammatory assay}

The carrageenan-induced paw edema in rats used in this in vivo anti-inflammatory assay releases various inflammatory mediators, and thus, this experiment was conducted to confirm if the $P$. insignis EtOAc extract present anti-inflammatory activity, considering the high amounts of morelloflavone extracted. The results obtained in the in vivo anti-inflammatory assay for the EtOAc extract from $P$. insignis shell incorporated in formulations F1 and F2 are shown in Figure 4.
The Tukey's post-test evidenced that the fruit extract incorporated in the formulations F1 and F2 significantly reduces paw edema when compared to the untreated group. Compared with the group receiving dexamethasone (positive control), a similar reduction was observed between the groups.

After $6 \mathrm{~h}$ of treatment, the anti-inflammatory effect was observed for the group treated with dexamethasone, reducing in $27.4 \%$ of the animals' paw edema. In the groups consisting in animals treated with the water solubilized extract, extract incorporated in F1 and extract incorporated in F2, the percentages of decrease of the edema were $29.2,31.0$, and $24.1 \%$, respectively, evidencing a greater inhibition of edema when treatment occurs with the extract incorporated into formulation $\mathrm{F} 1$.

It is most likely that the greater reduction of edema in the group treated with the extract incorporated in F1 is due to the behavior of phase and viscosity of the crystalline liquid that can affect both the release of the extract and the skin permeation since, in general, formulations with higher viscosity lead to a slow release of the active principle. Similar results of reduction of paw edema have been reported in the literature by da Silva et al. ${ }^{56}$ and Fonseca-Santos et al. ${ }^{57}$ that used LCS with procetyl as a surfactant as well.

In vivo anti-inflammatory assays have already been reported for morelloflavone by Otuki et al. ${ }^{50}$ however, this is the first time that this approach was applied for the evaluation of this activity in an extract containing a high amount of this compound.

The results obtained in the in vitro and in vivo antiinflammatory assays are contradictory. The in vitro

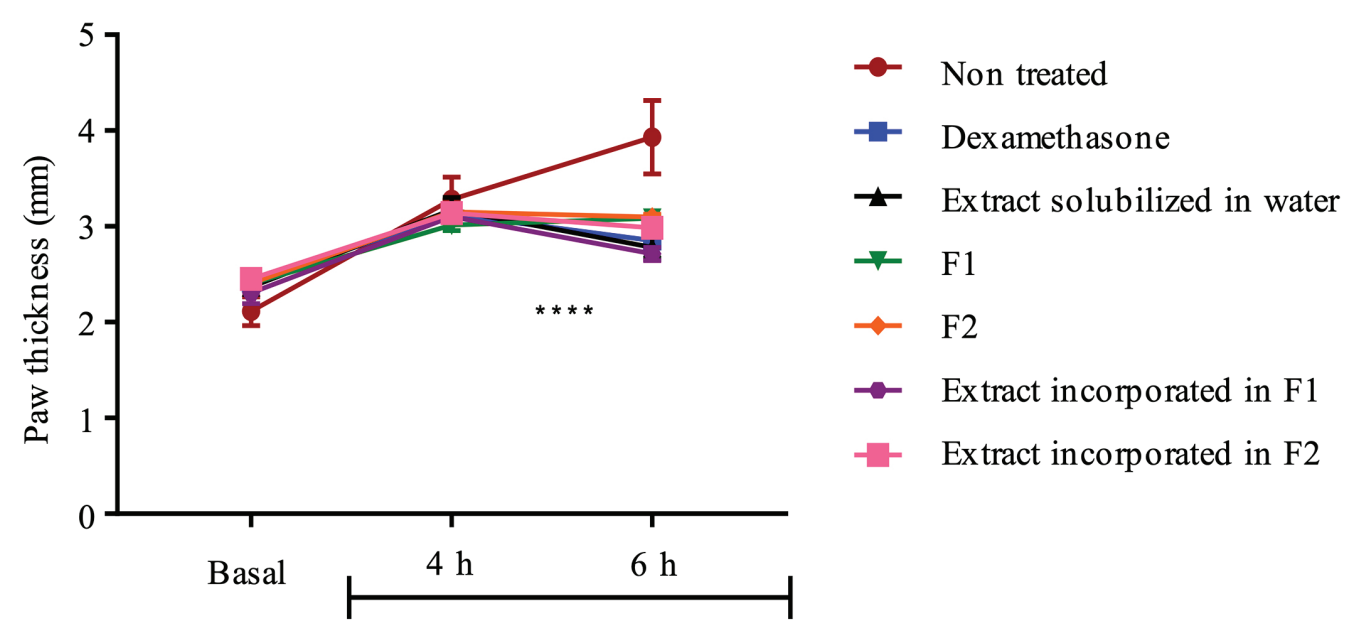

After induction of $\lambda$-carrageenan Inflamation

Figure 4. Anti-inflammatory activity results obtained for dexamethasone (positive control) at $1 \mathrm{mg} \mathrm{g}^{-1}$, solubilized extract at $400 \mu \mathrm{g} \mathrm{mL}^{-1}$, formulation $\mathrm{F} 1$, formulation F2, extract incorporated to F1 at $400 \mu \mathrm{g} \mathrm{g}^{-1}$, extract incorporated to F2 at $400 \mu \mathrm{g} \mathrm{g}^{-1}$ and negative control (not treated). Data are presented as mean \pm standard deviation of the results of five mice. The statistical significance of paw edema was analyzed using analysis of variance by Tukey's multiple comparison test; $* * * * p<0.05$. 
experiment with the extract did not show activity, while during the in vivo assay it was able to reduce paw edema by up to $31 \%$. These results show that one of the abiding weaknesses of in vitro experiments is that, sometimes, they might not be effective in replicating the precise cellular conditions of an organism.

\section{Conclusions}

This research provides a study of the chemical composition and biological activities of the Platonia insignis seeds and shell extracts. The results showed that the high antioxidant and anti-glycant activities present in the shell of bacuri can be attributed to the high concentration of the biflavonoid morelloflavone. Although four biflavonoids were identified in the seeds extract, it presented less pronounced bioactivities, being still important since this class of compounds is recognized for its antioxidant potential that can attribute high added value to the residues of the fruit. It is also possible to state that this residue can be used commercially as raw material for several sectors since its EtOAc extract obtained has extracted selectively an important biflavonoid. Finally, it was observed the maintenance of the biological activity of the extract incorporated into the drug carrier system, an important characteristic that can guarantee industrial and biomedical applicability to this residue for the treatment of several diseases.

\section{Supplementary Information}

Supplementary information (HPLC-DAD chromatograms, NMR and MS data and complementary results of the antiglycation assay and the crystalline system) is available free of charge at http://jbcs.sbq.org.br as PDF file.

\section{Acknowledgments}

The authors would like to thank the Coordination of Improvement of Higher Education Personnel (CAPES), the São Paulo Research Foundation (FAPESP) for the projects grants INCT-FAPESP (project No. 2014/50926-0), CEPIDFAPESP (project No. 2013/07600-3; 2016/16970-7), grant No. 2017/19870-6, and the scholarship provided to A. C. C. (grant No. 2017/18807-9), and the National Council of Technological and Scientific Development (CNPq) for the project grant INCT-CNPq (project No. 2014/465637-0) and the scholarship provided to D. C. R. (grant No. 159735/2017-3) and H. M. R. (grant No. 142014/2018-4).

\section{Author Contributions}

Dayane C. Ribeiro was responsible for the sample preparation, investigation, data curation and writing the original draft; Helena M. Russo for data curation, investigation, writing the original draft, review and editing; Karina Fraige for the investigation, data curation, validation of the HPLC method and writing review and editing; Cláudio R. Nogueira for NMR data curation; Maria L. Zeraik, Patrícia B. da Silva, Ana C. Codo, Giovana M. F. Calixto, Alexandra I. de Medeiros and Marlus Chorilli were responsible for the investigation of the bioassays; Vanderlan S. Bolzani was the supervisor of the project and responsible for the conceptualization, formal analysis and funding acquisition.

\section{References}

1. World Health Organization (WHO); World Health Statistics 2016: Monitoring Health for the SDGs, Sustainable Development Goals; WHO Press: Geneva, 2016, available at https://apps.who.int/iris/handle/10665/206498, accessed in November 2020.

2. Wolfender, J.-L.; Eugster, P. J.; Bohni, N.; Cuendet, M.; Chimia 2011, 65, 400.

3. Aguiar, L. P.; de Figueiredo, R. W.; Alves, R. E.; Maia, G. A.; de Souza, V. A. B.; Cienc. Tecnol. Aliment. 2008, 28, 423.

4. dos Santos Júnior, R. Q.; Soares, L. C.; Maia Filho, A. L. M.; de Sousa, K. A.; Santos, Í. M. S. P.; da Costa Júnior, J. S.; Saffi, J.; ConScientiae Saúde 2010, 9, 575.

5. de Carvalho, J. E. U.; Alves, S. M.; do Nascimento, W. M. O.; Müller, C. H.; Rev. Bras. Frutic. 2002, 24, 573.

6. Costa Júnior, J. S.; Ferraz, A. B. F.; Filho, B. A. B.; Feitosa, C. M.; Citó, A. M. G. L.; Freitas, R. M.; Saffi, J.; J. Med. Plants Res. 2011, 5, 293.

7. Junior, J. S. C.; Feitosa, C. M.; Cito, A. M. G.; de Freitas, R. M.; Henriques, J. A. P.; Saffi, J.; J. Biol. Sci. 2010, 10, 747.

8. Rufino, M. S. M.; Alves, R. E.; de Brito, E. S.; Pérez-Jiménez, J.; Saura-Calixto, F.; Mancini-Filho, J.; Food Chem. 2010, 121, 996.

9. Cavalcante, A. N.; Lima, L. K. F.; Araújo, C. M.; Santos, F. P. S.; do Nascimento, M. O.; e Sousa, J. M. C.; Rai, M.; Feitosa, C. M.; Toxicol. Rep. 2020, 7, 209.

10. Cavalcante, A. N.; Feitosa, C. M.; Santos, F. P. S.; de Sousa, A. P. R.; Sousa, R. S.; de Souza, A. A.; Pinto, B. F.; Araújo, C. M.; Rashed, K.; J. Mol. Struct. 2019, 1177, 286.

11. de Freitas, F. A.; Araújo, R. C.; Soares, E. R.; Nunomura, R. C. S.; da Silva, F. M. A.; da Silva, S. R. S.; de Souza, A. Q. L.; de Souza, A. D. L.; Franco-Montalbán, F.; Acho, L. D. R.; Lima, E. S.; Bataglion, G. A.; Koolen, H. H. F.; J. Food Biochem. 2018, 42, e12455. 
12. Lustosa, A. K. M. F.; Arcanjo, D. D. R.; Ribeiro, R. G.; Rodrigues, K. A. F.; Passos, F. F. B.; Piauilino, C. A.; SilvaFilho, J. C.; Araújo, B. Q.; Lima-Neto, J. S.; Costa-Júnior, J. S.; Carvalho, F. A. A.; Citó, A. M. G. L.; Rev. Bras. Farmacogn. 2016, 26, 77.

13. da Costa, J. S.; de Almeida, A. A. C.; Tomé, A. R.; Citó, A. M. G. L.; Saffi, J.; de Freitas, R. M.; Epilepsy Behav. 2011, 22, 678 .

14. Costa Júnior, J. S.; Ferraz, A. B. F.; Sousa, T. O.; Silva, R. A. C.; de Lima, S. G.; Feitosa, C. M.; Citó, A. M. G. L.; Cavalcante, A. A. C. M.; Freitas, R. M.; Sperotto, A. R. M.; Péres, V. F.; Moura, D. J.; Saffi, J.; Basic Clin. Pharmacol. Toxicol. 2013, $112,34$.

15. Arcanjo, D. D. R.; da Costa-Júnior, J. S.; Moura, L. H. P.; Ferraz, A. B. F.; Rossatto, R. R.; David, J. M.; Quintans-Júnior, L. J.; Oliveira, R. C. M.; Citó, A. M. G. L.; de Oliveira, A. P.; Nat. Prod. Res. 2014, 28, 923.

16. Edet, A.; Olorunfemi, E.; Aniebiet, E.; Isiguzoro, I.; Afr. J. Pharm. Pharmacol. 2015, 9, 154.

17. Silva, A. P.; Silva, M. P.; Oliveira, C. G.; Monteiro, D. C.; Pinto, P. L.; Mendonça, R. Z.; Costa Júnior, J. S.; Freitas, R. M.; de Moraes, J.; Toxicol. In Vitro 2015, 29, 681.

18. da Silva, A. F.; da Rocha, C. Q.; da Silva, L. C. N.; Carvalho Júnior, A. R.; Mendes, I. N. F. V.; de Araruna, A. B.; Motta, E. P.; Silva, R. S.; Campos, C. D. L.; Farias, J. R.; Oliveira, A. S.; Silva, D. H. D. S.; Nascimento, F. R. F.; Guerra, R. N. M.; Monteiro, C. A.; Pathogens 2020, 9, 84.

19. Atoui, A. K.; Mansouri, A.; Boskou, G.; Kefalas, P.; Food Chem. 2005, 89, 27.

20. de Camargo, A. C.; Biasoto, A. C. T.; Schwember, A. R.; Granato, D.; Rasera, G. B.; Franchin, M.; Rosalen, P. L.; Alencar, S. M.; Shahidi, F.; Food Chem. 2019, 290, 229.

21. Ghasemian, M.; Owlia, S.; Owlia, M. B.; Adv. Pharmacol. Sci. 2016, 2016, 9130979.

22. Gabboun, N. H.; Najib, N. M.; Ibrahim, H. G.; Int. J. Pharm. 2001, 212, 73.

23. Boyd, B. J.; Whittaker, D. V.; Khoo, S.-M.; Davey, G.; Int. J. Pharm. 2006, 318, 154.

24. International Council on Harmonization of Technical Requirements for Registration of Pharmaceuticals for Human Use (ICH); Validation of Analytical Procedures: Text Methodology Q2 (R1); ICH: Geneva, 2005.

25. Fraige, K.; Dametto, A. C.; Zeraik, M. L.; de Freitas, L.; Saraiva, A. C.; Medeiros, A. I.; Castro-Gamboa, I.; Cavalheiro, A. J.; Silva, D. H. S.; Lopes, N. P.; Bolzani, V. S.; Phytochem. Anal. 2018, 29, 196.

26. Lunceford, N.; Gugliucci, A.; Fitoterapia 2005, 76, 419.

27. Fonseca-Santos, B.; Pacheco, C. N.; Pinto, M. C.; Chorilli, M.; Ind. Crops Prod. 2019, 128, 488.

28. Fonseca-Santos, B.; Bonifácio, B. V.; Baub, T. M.; Gremião, M. P. D.; Chorilli, M.; J. Biomed. Nanotechnol. 2019, 15, 1334.
29. Vinegar, R.; Schreiber, W.; Hugo, R.; J. Pharmacol. Exp. Ther. 1969, 166, 96.

30. Masuda, T.; Yamashita, D.; Takeda, Y.; Yonemori, S.; Biosci. Biotechnol. Biochem. 2005, 69, 197.

31. Jamila, N.; Khairuddean, M.; Khan, S. N.; Khan, N.; Magn. Reson. Chem. 2014, 52, 345.

32. Li, X.-C.; Joshi, A. S.; Tan, B.; ElSohly, H. N.; Walker, L. A.; Zjawiony, J. K.; Ferreira, D.; Tetrahedron 2002, 58, 8709.

33. Aravind, A. P. A.; Menon, L. N.; Rameshkumar, K. B. In Diversity of Garcinia Species in the Western Ghats: Phytochemical Perspective; Rameshkumar, K. B., ed.; Jawaharlal Nehru Tropical Botanic Garden and Research Institute: Thiruvananthapuram, India, 2017, p. 19-75.

34. Ren, Y.; Lantvit, D. D.; de Blanco, E. J. C.; Kardono, L. B. S.; Riswan, S.; Chai, H.; Cottrell, C. E.; Farnsworth, N. R.; Swanson, S. M.; Ding, Y.; Li, X.-C.; Marais, J. P. J.; Ferreira, D.; Kinghorn, A. D.; Tetrahedron 2010, 66, 5311.

35. Gil, B.; Sanz, M. J.; Terencio, M. C.; Gunasegaran, R.; Payá, M.; Alcaraz, M. J.; Biochem. Pharmacol. 1997, 53, 733.

36. Osorio, E.; Londoño, J.; Bastida, J.; Molecules 2013, 18, 6092.

37. Li, X.; Ai, H.; Sun, D.; Wu, T.; He, J.; Xu, Z.; Ding, L.; Wang, L.; Oncol. Lett. 2016, 12, 3373.

38. Peng, X.; Cheng, K.-W.; Ma, J.; Chen, B.; Ho, C.-T.; Lo, C.; Chen, F.; Wang, M.; J. Agric. Food Chem. 2008, 56, 1907.

39. Lin, Y. M.; Anderson, H.; Flavin, M. T.; Pai, Y. H. S.; MataGreenwood, E.; Pengsuparp, T.; Pezzuto, J. M.; Schinazi, R. F.; Hughes, S. H.; Chen, F. C.; J. Nat. Prod. 1997, 60, 884.

40. Carrillo-Hormaza, L.; Ramírez, A. M.; Quintero-Ortiz, C.; Cossio, M.; Medina, S.; Ferreres, F.; Gil-Izquierdo, A.; Osorio, E.; J. Funct. Foods 2016, 27, 503.

41. Compagnone, R. S.; Suarez, A. C.; Leitao, S. G.; Delle Monache, F.; Rev. Bras. Farmacogn. 2008, 18, 6.

42. Huang, D.; Ou, B.; Prior, R. L.; J. Agric. Food Chem. 2005, 53, 1841.

43. Gontijo, V. S.; de Souza, T. C.; Rosa, I. A.; Soares, M. G.; da Silva, M. A.; Vilegas, W.; Viegas, C.; dos Santos, M. H.; Food Chem. 2012, 132, 1230.

44. Gil, E. S.; Couto, R. O.; Rev. Bras. Farmacogn. 2013, 23, 542.

45. Ho, S.-C.; Wu, S.-P.; Lin, S.-M.; Tang, Y.-L.; Food Chem. 2010, 122,768 .

46. Magadula, J.; Mbwambo, Z.; Gatto, J.; Derbré, S.; Guilet, D.; Richomme, P.; Eur. J. Med. Plants 2014, 4, 1336.

47. Abdallah, H. M.; El-Bassossy, H. M.; Mohamed, G. A.; El-Halawany, A. M.; Alshali, K. Z.; Banjar, Z. M.; J. Nat. Med. 2017, 71, 216.

48. e Silva, A. K. F.; dos Reis, A. C.; Pinheiroc, E. E. A.; de Sousa, J. N.; Oliveira, F. A. A.; Moura, A. K. S.; Lima Neto, J. S.; Citó, A. M. G. L.; de Siqueira-Júnior, J. P.; Kaatz, G. W.; Barreto, H. M.; Curr. Drug Metab. 2020, 21, DOI: 10.2174/13892002216 66200523155617. 
49. Taher, M.; Aminuddin, A.; Susanti, D.; Aminudin, N. I.; On, S.; Ahmad, F.; Hamidon, H.; Nat. Prod. Sci. 2016, 22, 122.

50. Otuki, M. F.; Bernardi, C. A.; Prudente, A. S.; Laskoski, K.; Gomig, F.; Horinouchi, C. D. S.; Guimarães, C. L.; Ferreira, J.; Delle-Monache, F.; Cechinel-Filho, V.; Cabrini, D. A.; Basic Clin. Pharmacol. Toxicol. 2011, 109, 56.

51. Nile, S. H.; Park, S. W.; Mini-Rev. Med. Chem. 2013, 13, 95.

52. Yang, H.; Xiang, J.; Dong, J.; Cheng, J.; Zheng, X.; Liu, P.; Wu, R.; Lv, Y.; J. Liver 2018, 7, 227.

53. Calixto, G.; Duque, C.; Aida, K.; dos Santos, V. R.; Massunari, L.; Chorilli, M.; Int. J. Nanomed. 2018, 13, 31.

54. Fujimura, A. T.; Martinez, R. M.; Pinho-Ribeiro, F. A.; da Silva, A. M. L. D.; Baracat, M. M.; Georgetti, S. R.; Verri, W. A.; Chorilli, M.; Casagrande, R.; J. Nat. Prod. 2016, 79, 1329.
55. Cintra, G.; Pinto, L.; Calixto, G.; Soares, C.; Von Zuben, E.; Scarpa, M.; Gremião, M.; Chorilli, M.; Molecules 2016, 21, 231.

56. da Silva, P. B.; Calixto, G. F.; Oshiro Júnior, J.; Bombardelli, R.; Fonseca-Santos, B.; Rodero, C.; Chorilli, M.; Polymers 2017, 9,30 .

57. Fonseca-Santos, B.; Satake, C. Y.; Calixto, G.; dos Santos, A. M.; Chorilli, M.; Int. J. Nanomed. 2017, 12, 6883.

Submitted: May 15, 2020 Published online: November 19, 2020 